\title{
Enolase isoenzymes in the cerebrospinal fluid of patients with diseases of the nervous system
}

\author{
JANICE A ROYDS, ${ }^{*}$ G AELWYN B DAVIES-JONES, $†$ NORMAN A LEWTAS, $\ddagger$ \\ WALTER R TIMPERLEY,§ C BRIAN TAYLOR* \\ From the Department of Biochemistry, The University of Sheffield, ${ }^{*}$ the Departments of Neurology, $\dagger$ \\ Radiology $\ddagger$ and Neuropathology,§ The Royal Hallamshire Hospital, Sheffield, UK
}

SUMMARY Alpha and gamma enolase isoenzymes have been studied in 212 patients with a variety of neurological diseases. The results show that these proteins are sensitive markers of tissue damage which enable a distinction to be made between the involvement of glial and neuronal components.

In a previous comparative study, Royds et al measured the total activities of aldolase, enolase, pyruvate kinase, lactate dehydrogenase and creatine kinase in cerebrospinal fluid of 121 patients with disorders of the central nervous system. ${ }^{1}$ They concluded that of these five cerebrospinal fluid enzymes, enolase was the most sensitive marker of neurological disease, especially in the detection of low grade astrocytomas. Enolase is a dimeric enzyme with three subunit types, $\alpha, \beta$ and $\gamma$, which give rise to five isoenzymes, $\alpha \alpha, \beta \beta, \gamma \gamma, \alpha \beta$ and $\alpha \gamma .^{23}$ These show differential cellular distributions, and of particular interest are the isoenzyme patterns in the nervous system. ${ }^{45}$ Glial cells contain only $\alpha \alpha$ enolase, whereas $\gamma \gamma$ is confined to the neurons. Outside the nervous system $\gamma$ enolase occurs predominantly in the cells of the diffuse neuroendocrinological system. ${ }^{6}$ The determination of isoenzyme levels, rather than total activities of enolase, might be expected to reflect more accurately the nature of the lesion. Thus, for example, elevated levels of $\gamma$ enolase in the cerebrospinal fluid should reflect neuronal damage.

Enolase isoenzymes have already been used as differential markers in the histological localisation in human brain tumours. ${ }^{7}$ Decrease of $\gamma \gamma$ enolase levels in the basal ganglia has been reported in necropsy samples in Huntingdon's disease. ${ }^{8}$ Cerebrospinal fluid concentrations of $\gamma \gamma$ enolase were shown

Address for reprint requests: Dr WR Timperley, Royal Hallamshire Hospital, Glossop Road, Sheffield S10 2JF, UK.

Received 18 March 1983 and in revised form 11 May 1983. Accepted 31 May 1983 to rise in experimental bilirubin encephalopathy of the rat ${ }^{9}$ and recently elevation of $\gamma \gamma$ enolase has been shown in the cerebrospinal fluid of patients in comatose states due to anoxia, head injury, sepsis, cirrhosis and fulminating hepatitis, although normal levels were found in meningitis. ${ }^{10}$ Gamma enolase has also been used as a marker for tumours of the diffuse neuroendocrinological system and the intensity of staining for this isoenzyme has been shown to be related to the degree of malignancy in dermal and ocular melanomas. ${ }^{112}$ Furthermore, measurement of serum $\gamma$ enolase in patients with oat cell carcinoma of the lung suggests that it may be a useful marker for staging the lesion and monitoring therapeutic response. ${ }^{13}$

In the present study we report changes in $\alpha$ and $\gamma$ immunoreactive enolase in the cerebrospinal fluid of 212 patients with neurological diseases.

\section{Methods}

Human $\alpha \alpha$ and $\gamma \gamma$ enolases were prepared from brains obtained within twenty-four hours of death and the purified proteins were then used to raise monospecific antisera in rabbits as previously described. ${ }^{7}$

\section{Radioimmunoassay}

Ten micrograms of each purified protein were iodinated using $\mathrm{N}$-succinimidyl-3,4 hydroxyl-5( $\left(^{125}\right)$ iodophenylpropionate (Amersham International Ltd, Amersham, Bucks, England) by the Bolton and Hunter method. ${ }^{14}$ The iodinated protein was separated from the low molecular weight products of the reaction using a $10 \mathrm{ml}$ column of Sephadex G-25 (coarse grade) equilibrated with $50 \mathrm{mM}$ sodium phosphate buffer, $\mathrm{pH} 7.5$, containing $0.25 \%$ gelatine (Sigma London, Fancy Road, Poole, Dorset, Eng- 
land). Radiolabelled proteins with a specific activity of approximately $20 \mu \mathrm{C} / \mu \mathrm{g}$ were thus obtained and stored at $-20^{\circ} \mathrm{C}$ in $50 \%$ glycerol. The assay was performed in LP3 tubes (Luckham, Burgess Hill, Sussex, England). All dilutions were made in phosphate, bovine serum albumin, saline (PBS) buffer of the following composition: $50 \mathrm{mM}$ phosphate buffer, pH 7.5 containing $0.7 \% \mathrm{NaCl}, 0.7 \%$ BSA-Sigma RIA grade.

Anti- $\alpha \alpha$ enolase serum and anti- $\gamma \gamma$ enolase serum were used at dilutions of 1 in 2000 and 1 in 800 respectively. The following additions were made to the tubes in order: $100 \mu \mathrm{l}$ PBS, $100 \mu \mathrm{l}$ primary antiserum, and $100 \mu \mathrm{l}$ of unknown or standard enolase solutions. After incubation at $4^{\circ} \mathrm{C}$ for four hours, $100 \mu \mathrm{l}$ of iodinated protein solution containing approximately $5000 \mathrm{cpm}$ were added. The tubes were incubated overnight at $4^{\circ} \mathrm{C}$ and the following additions were then made: $100 \mu \mathrm{l} 0.1 \mathrm{M}$ EDTA, $\mathrm{pH} 7.5$, $100 \mu$ l of a 1 in 100 dilution of non-immune rabbit serum (Eivai Bius Ltd, PO Box 37, Horsham, Sussex, England), and $100 \mu$ l of a 1 in 5 dilution of goat anti-rabbit IgG (Miles Ltd, Stoke Poges, Slough, England). After incubation at room temperature for four hours, the tubes were centrifuged at $1300 \mathrm{~g}$ in an MSE Mistral 6L for 30 minutes, the supernatants removed by aspiration and the pellets counted in an Intertechnique well-type gamma counter. Pure enolase enzymes giving only one band on SDS-gel electrophoresis were used as standards in the assay. Aliquots of a suitably diluted human brain supernatant were frozen and used to provide between-batch controls. All determinations were done in duplicate and a standard curve was included with each experiment. Cerebrospinal fluid samples were pooled and concentrated $\times 80$ in Minicon concentrators (Amicon Ltd, 57 Queens Road, High Wycombe, Bucks, England). A range of dilutions of these concentrated cerebrospinal fluid samples was then assayed and evidence for parallelism with the standard curve sought. The efficiency of recovery for purified enolase isoenzymes from cerebrospinal fluid was also determined by adding increasing amounts of purified $\alpha \alpha$ or $\gamma \gamma$ enolase cerebrospinal fluid (initial levels of $9.0 \mathrm{ng} / \mathrm{ml}$ and $3.7 \mathrm{ng} / \mathrm{ml}$ for $\alpha$ and $\gamma$ enolase respectively) and the amounts present were then measured by radioimmunoassay.

\section{Samples}

$0 \cdot 5$ cc of each CSF was centrifuged onto a microscope slide in a Shandon Cytospin 2 (Shandon Southern Products Limited, UK) and the deposit stained with haematoxylin and eosin. Samples containing more than an occasional red blood cell on microscopical examination were excluded from the study. Xanthochromic samples were also discarded. This method of assessment would certainly exclude samples with more than ten red blood cells per cubic millimetre. A contamination of this level would contribute only $0.25 \mathrm{ng} / \mathrm{ml} \alpha$ enolase and $0.025 \mathrm{ng} / \mathrm{ml} \gamma$ enolase to the CSF if these cells were lysed. All samples were centrifuged to remove cells before storage at $-20^{\circ} \mathrm{C}$.

\section{Results}

RADIOIMMUNOASSAY

Typical standard curves for the radioimmunoassay
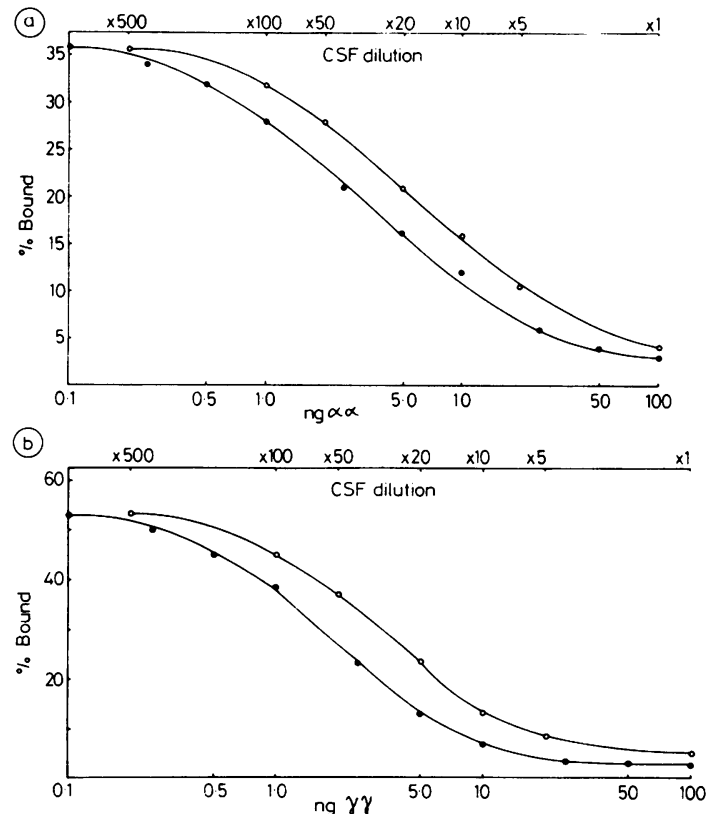

Fig 1(a) Dilution characteristics of $\alpha$ and $\gamma$ enolase immunoreactivity in CSF and (b) in the purified isoenzymes

of immunoreactive $\alpha$ and $\gamma$ enolase are shown in figs $1 \mathrm{a}$ and $\mathrm{b}$ respectively. The approximate minimum detectable amounts of enolase in these assays was $500 \mathrm{pg}$ for the immunoreactive $\alpha$ enolase and $200 \mathrm{pg}$ for the $\gamma$. These amounts give approximately $5 \%$ displacement of the total tracer added, with a stan dard deviation of $1.2 \%$ in quadruple estimations.

The interassay variability as determined by assaying standard isoenzyme solutions containing 6.0 $\mathrm{ng} / \mathrm{ml}$ was less than $10 \%$. No significant crossreactivity between $\alpha$ and $\gamma$ enolase systems was detected.

The immunoreactivity present in cerebrospinal fluid diluted out in parallel with the standard curve of the radioimmunoassay (see figs $1 \mathrm{a}$ and $\mathrm{b}$ ), demonstrating that enolase isoenzymes in cerebrospinal fluid and in the purified standards behave in an immunologically identical manner in this system: Additions of the purified $\alpha \alpha$ and $\gamma \gamma$ enolase isoenzymes to cerebrospinal fluid produced a quantitative recovery of immunoreactivity when assayed (see table).

LEVELS OF IMMUNOREACTIVE $\alpha$ AND $\gamma$ ENOLASE IN CEREBROSPINAL FLUID OF PATIENTS WITH AND WITHOUT NEUROLOGICAL DISEASE

Control cerebrospinal fluid samples obtained from patients undergoing myelography or from patients who had no organic neurological disease contained 
Table Recovery of purified $\gamma$ enolase from human CSF

\begin{tabular}{|c|c|c|c|c|}
\hline Amount added $n g / m l$ & \multicolumn{2}{|c|}{ Amount measured $\mathrm{ng} / \mathrm{ml}$} & \multicolumn{2}{|c|}{ Recovery \% } \\
\hline $\begin{array}{r}0 \cdot 0 \\
5 \cdot 0 \\
10 \cdot 0 \\
50 \cdot 0 \\
100 \cdot 0\end{array}$ & $\begin{array}{c}\alpha \alpha \\
9.0 \pm 0.18 \\
13.85 \pm 0.3 \\
19.6 \pm 0.77 \\
59.9 \pm 0.96 \\
108.27 \pm 2.5\end{array}$ & $\begin{array}{l}\gamma \gamma \\
3.7 \pm 0.16 \\
8.85 \pm 0.26 \\
13.4 \pm 0.55 \\
53.2 \pm 0.57 \\
105.4 \pm 2.5\end{array}$ & $\begin{array}{r}\alpha \alpha \\
100 \cdot 0 \\
98 \cdot 9 \\
103 \cdot 0 \\
101 \cdot 5 \\
99 \cdot 0\end{array}$ & $\begin{array}{r}\gamma \gamma \\
100 \cdot 0 \\
101 \cdot 7 \\
97 \cdot 8 \\
99 \cdot 0 \\
101 \cdot 6\end{array}$ \\
\hline
\end{tabular}

These values are the means \pm standard deviations of quadruple determinations.

$5 \cdot 0+\mathrm{SD} 2 \cdot 7 \mathrm{ng} / \mathrm{ml}$ immunoreactive $\alpha$ enolase and $3.0+\mathrm{SD} 2.4 \mathrm{ng} / \mathrm{ml}$ immunoreactive $\gamma$ enolase. The maximum normal levels for enolase in normal cerebrospinal fluid were taken as $10.4 \mathrm{ng} / \mathrm{ml}$ for $\alpha$ and $8.0 \mathrm{ng} / \mathrm{ml}$ for $\gamma$, these being the mean control values plus two standard deviations. The results for $\alpha$ and $\gamma$ immunoreactive enolase in the cerebrospinal fluid of patients with various neurological disorders are seen in figs 2 to 6 .

Over $70 \%$ of patients with multiple sclerosis were found to have raised levels of $\alpha$ enolase in the cerebrospinal fluid but only $30 \%$ had raised $\gamma$. However, no significant differences could be detected in the levels of $\alpha$ or $\gamma$ isoenzyme between the groups with acute or chronic multiple sclerosis or those with optic neuritis (see fig 2), although the means for all groups were elevated above control values. It is of interest that $73 \%$ of patients with multiple sclerosis whose $\alpha$ enolase levels exceeded $25 \mathrm{ng} / \mathrm{ml}$ also showed elevated IgG ratios, whereas this ratio was

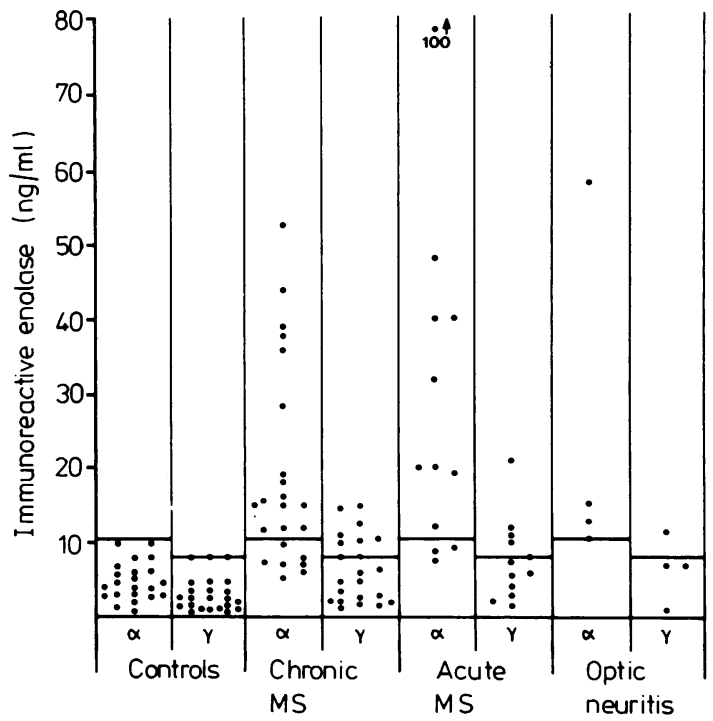

Fig 2 Immunoreactive $\alpha$ and $\gamma$ enolase in the control group and in the patients with multiple sclerosis. The horizontal bars indicate the maximum levels of enolase isoenzymes in control CSF. raised in only $20 \%$ of patients with $\alpha$ enolase below $25 \mathrm{ng} / \mathrm{ml}$.

Alpha enolase was raised in approximately $80 \%$ of the cerebrospinal fluid samples from patients with primary tumours and in all three with metastatic deposits. However, although all the patients with metastases had elevated $\gamma$ enolase in the cerebrospinal fluid, only four of the twenty-four patients with primary tumours showed such a rise and of these, two had acoustic neuromas, one a craniopharyngioma and one a pituitary adenoma (see fig 3 ).

Several patients with dementia had elevated levels of both $\alpha$ and $\gamma$ enolase in the cerebrospinal fluid; however, the mean levels for $\alpha$ enolase in senile dementia was $9.7+\mathrm{SE} 1.2 \mathrm{ng} / \mathrm{ml}$, whereas the value for those with pre-senile dementia was $28 \cdot 0+7 \cdot 2$ $\mathrm{ng} / \mathrm{ml}$ (see fig 4 ).

The levels of immunoreactive $\alpha$ enolase were raised in eight out of nine patients who had suffered epileptic fits within five days prior to lumbar punc-

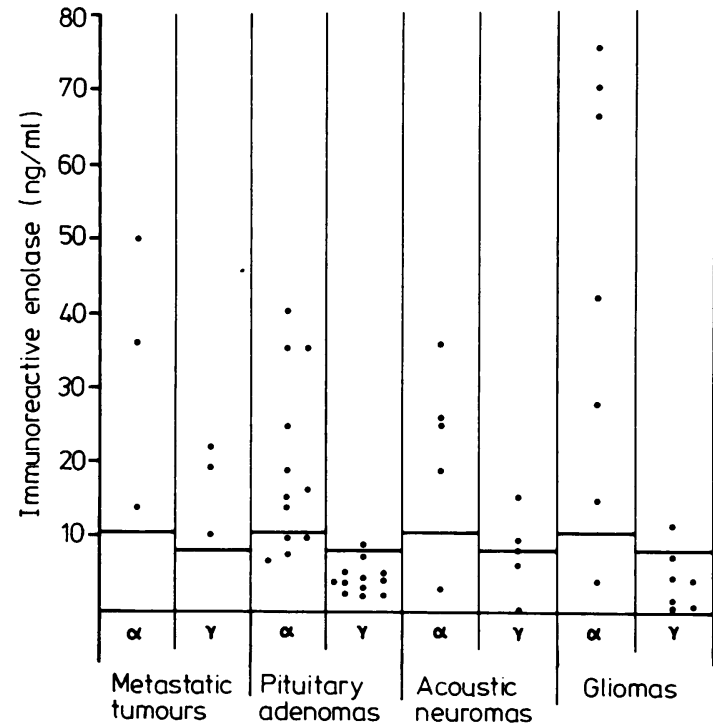

Fig 3 Immunoreactive $\alpha$ and $\gamma$ enolase in cerebrospinal fuid of patients with primary and secondary brain neoplasm; results grouped according to diagnosis. 


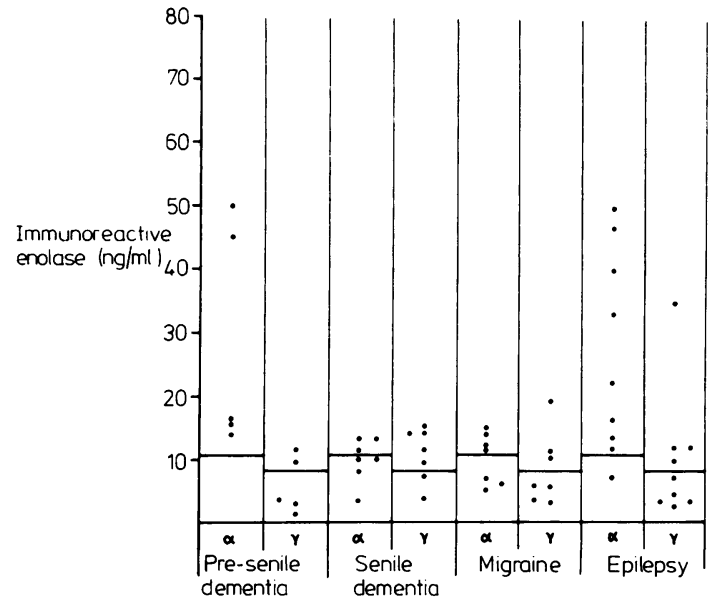

Fig 4 Immunoreactive $\alpha$ and $\gamma$ enolase in the cerebrospinal fluid of patients with dementia, migraine or epilepsy.

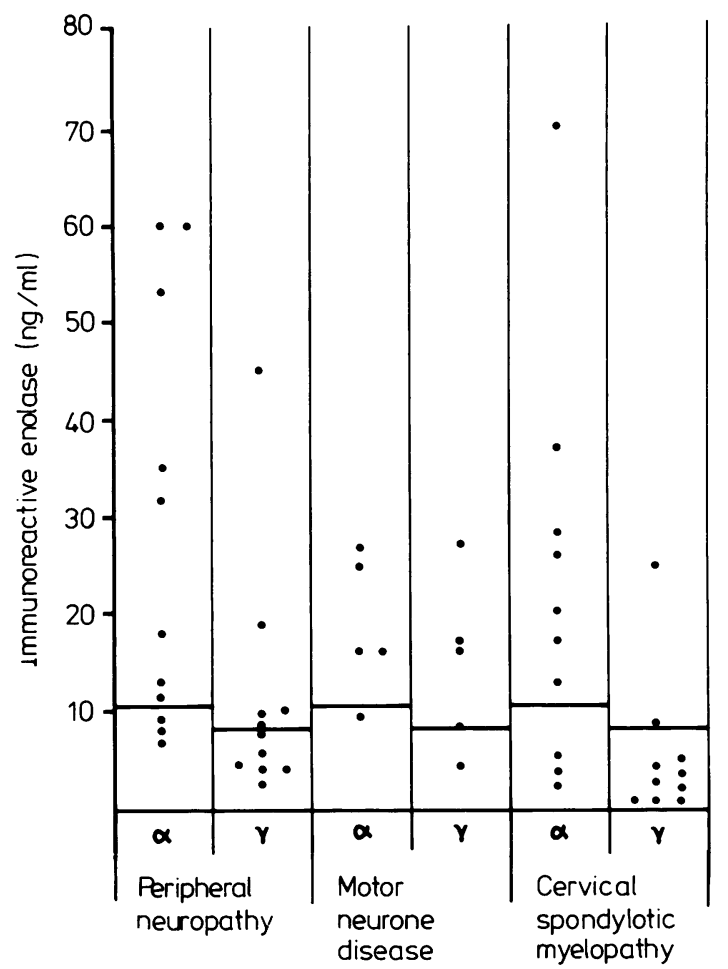

Fig 5 Immunoreactive $\alpha$ and $\gamma$ enolase in the cerebrospinal fluid; results grouped according to diagnosis.

ture, whereas only four of these patients had raised $\gamma$ enolase (see fig 4). The highest $\gamma$ enolase value $(35.1 \mathrm{ng} / \mathrm{ml})$ occurred in a patient who exhibited

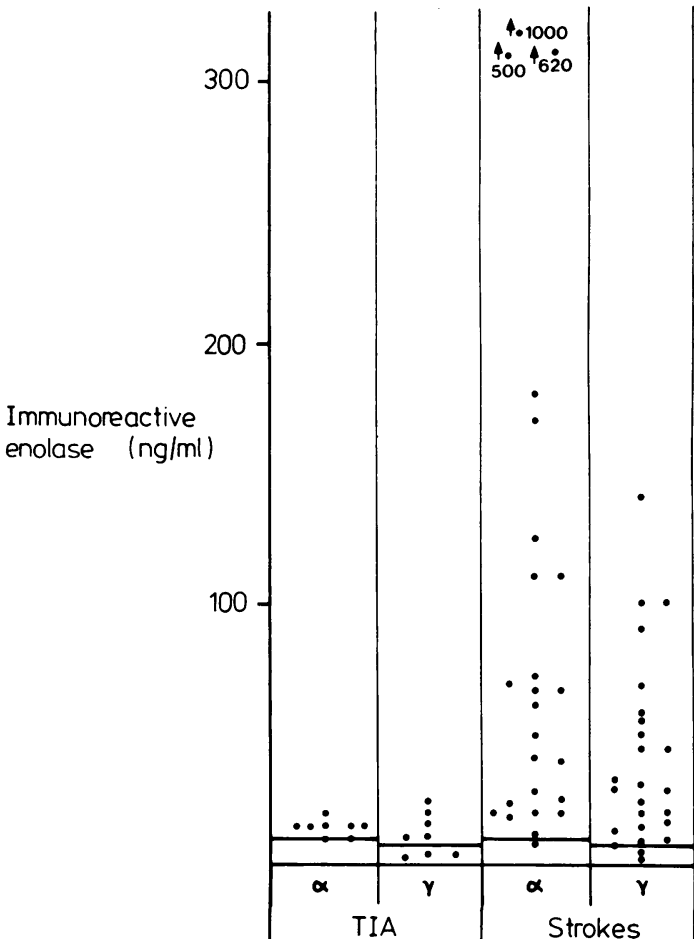

Fig 6 Immunoreactive $\alpha$ and $\gamma$ enolase in the cerebrospinal fluid of patients who have suffered transient ischaemic attacks or strokes.

continuous seizure activity electrophysiologically.

Two cases of peripheral neuropathy showed $\gamma$ enolase levels above $10 \mathrm{ng} / \mathrm{ml}$ (see fig 5). One, in which the value was $45 \mathrm{ng} / \mathrm{ml}$, was from a patient with an axonal neuropathy. The other case, in which the $\gamma$ enolase level was $19 \mathrm{ng} / \mathrm{ml}$, showed low levels of folate and $B_{12}$ in the serum but no clinical signs of CNS involvement at the time of the lumbar puncture.

Alpha and $\gamma$ enolase levels were elevated in most patients with cerebral infarction or transient ischaemic attacks within five days prior to lumbar puncture (see fig 6). The mean values for enolase isoenzyme levels in the cerebrospinal fluid of patients with cerebral infarction were higher than those who had suffered transient ischaemic attacks. The respective values for $\alpha$ enolase in the two groups being $132.8+\mathrm{SE} 43.4 \mathrm{ng} / \mathrm{ml}$ and $13.5+\mathrm{SE}$ $1.0 \mathrm{ng} / \mathrm{ml}(\mathrm{p}<0.01)$ and for $\gamma$ enolase $38.5+\mathrm{SE}$ $6.8 \mathrm{ng} / \mathrm{ml}$ and $11.3+$ SE $2.7 \mathrm{ng} / \mathrm{ml}(\mathrm{p}<0.001)$.

Some interesting individual cases did not fall into any of the main categories used in the figures. One patient with Huntington's chorea had a value for $\gamma$ 
enolase of $18 \mathrm{ng} / \mathrm{ml}$ but normal $\alpha$ enolase (7.0 ng/ $\mathrm{ml})$. Of particular interest were the two cases of herpes simplex encephalitis in which the cerebrospinal fluid $\alpha$ levels were 110 and $135 \mathrm{ng} / \mathrm{ml} \mathrm{respec-}$ tively and those for $\gamma$ enolase 30 and $23 \mathrm{ng} / \mathrm{ml}$.

\section{Discussion}

This paper presents the results of a study of $\alpha$ and $\gamma$ immunoreactive enolase in the cerebrospinal fluid measured by radioimmunoassay in 212 patients with a variety of neurological disorders including strokes, herpes simplex encephalitis, migraine, epilepsy, dementia, multiple sclerosis, myelopathy, motor neuron disease and various types of neoplasm.

In measuring the level of enzymes in cerebrospinal fluid, the possibility of interference by haemolysed red cells must be considered. The exclusion of xanthochromic samples and those containing significant numbers of red blood cells overcame this problem in the present study.

The results show that $\alpha$ enolase is a sensitive but non-specific marker of neurological disease, the level being raised in a substantial proportion of patients in every category studied. The origin of the $\alpha$ enolase in the cerebrospinal fluid is not certain. Although its cellular distribution within the CNS would indicate a glial origin, it may also arise as a result of impairment of the blood-brain barrier since serum $\alpha$ enolase exceeds that in the cerebrospinal fluid by one to two orders of magnitude. Thus it is probable that the very high $\alpha$ enolase levels found in cases of extensive cerebral infarction are at least in part derived from serum. In this study the $\gamma$ enolase is raised in fewer patients and to a smaller extent than $\alpha$ enolase. The relatively low serum level of the $\gamma$ isoenzyme and its cellular distribution within the central nervous system indicates a neuronal origin for the cerebrospinal fluid $\gamma$ enolase. This is consistent with the elevation of $\gamma$ enolase in diseases resulting in neuronal damage, such as herpes simplex encephalitis, Huntington's chorea and metastatic tumours.

The degree of sensitivity is clearly shown by a rise in both $\alpha$ and $\gamma$ enolase in the majority of cases of epilepsy and transient ischaemic attacks, and in approximately half of the cases of migraine. The highest levels are seen in acute processes, resulting in tissue necrosis such as cerebral infarction, herpes simplex encephalitis and neoplasia.

No significant differences were seen in the activity of the two isoenzymes in cases of acute and chronic multiple sclerosis (see fig 2). It seems likely that $\alpha$ enolase levels reflect active demyelination which can sometimes be extremely difficult to detect clinically.
As would be expected, of the two isoenzymes, $\alpha$ enolase shows the most marked rise in these cases but it is also of interest that some cases showed a rise of $\gamma$ enolase, presumably reflecting damage to axons passing through areas of demyelination. The highest values for $\alpha$ enolase occurred in patients with the highest cerebrospinal fluid immunoglobulin ratio.

The majority of cases of peripheral neuropathy showed a rise in activity of $\alpha$ enolase and in some cases this was quite marked. Patients with motor neuron disease, on the other hand, showed a rise in both $\alpha$ and $\gamma$ enolase and this was also seen in cases of myelopathy due to cord compression by cervical discs, the rise in $\gamma$ enolase presumably reflecting damage to neurons within the spinal cord.

Largely owing to the difficulties in obtaining cerebrospinal fluid from patients with tumours of the nervous system, the series contains relatively few cases. However, $\alpha$ enolase does appear to be a sensitive marker for the presence of brain tumours, elevated levels being found even in cases of benign neoplasms such as acoustic neuromas and pituitary adenomas. Two cases of acoustic neuroma also showed a rise in $\gamma$ enolase activity, which may reflect axonal damage in the nerve itself or within the brain stem. The more rapidly growing neoplasms such as metastatic gliomas showed marked rises in both isoenzymes.

In conclusion, enolase is a very sensitive marker of neurological disease and assay of the $\alpha$ and $\gamma$ isoenzymes appears to reflect damage to glia and neurons respectively. There may be a useful relationship between isoenzyme levels and the extent of tissue damage.

The authors thank Miss Pauline Little for her technical assistance and Mrs P Kirk for typing the manuscript. Financial support from the Wellcome Trust (Grant number 11353/1.5) and from the Special Trust for the Former United Sheffield Hospitals (Grant number 276) is gratefully acknowledged.

\section{References}

${ }^{1}$ Royds JA, Timperley WR, Taylor CB. Levels of enolase and other enzymes in the cerebrospinal fluid as indices of pathological change.J Neurol Neurosurg Psychiatry $1981 ; 44: 1129-35$.

${ }^{2}$ Rider CC, Taylor CB. Enolase isoenzymes in rat tissues. Biochim Biophys Acta 1974;365:285-300.

${ }^{3}$ Fletcher L, Rider CC, Taylor CB. Enolase isoenzymes III. Chromatographic and immunological characteristics of rat brain enolase. Biochim Biophys Acta 1976;452:245-52.

${ }^{4}$ Schmechel DE, Marangos PJ, Zis AP, Brightman M, Goodwin FK. The brain enolases as specific markers 
of neuronal and glial cells. Science 1978;199:313-5.

5 Marangos PJ, Schmechel DE. The neurobiology of the brain enolases. In: Youdim MBH, Lovenberg W, Sharman DE, Lagnado JR, eds. Essays in Neurochemistry and Neuropharmacology 1980;4: 211-47.

${ }^{6}$ Schmechel DE, Marangos PJ, Brightman M. Neuronespecific enolase is a molecular marker for peripheral and central neuroendocrine cells. Nature 1978; 276:834-6.

${ }^{7}$ Royds JA, Parsons MA, Taylor CB, Timperley WR. Enolase isoenzyme distribution in the human brain and its tumours. $J$ Pathol 1982;137:37-49.

${ }^{8}$ Marangos PJ, Paul SM. Brain levels of neurone-specific and non-neuronal enolase in Huntington's disease. $J$ Neurochem 1981;37:1338-40.

${ }^{9}$ Semba R, Kato K. Increased nervous system-specific enolases in rat plasma and cerebrospinal fluid in bilirubin encephalopathy detected by an enzyme immunoassay. $J$ Neurochem 1982;39:360-5.
${ }^{10}$ Scarna H, Delafosse B, Steinberg R, et al. Neuronespecific enolase as a marker of neuronal lesions during various comas in man. Neurochem Internat 1982;4:405-11.

" Royds JA, Parsons MA, Rennie IG; Timperley WR, Taylor CB. Enolase isoenzymes in benign and malignant melanocytic lesions. Diagnostic Histopathol 1982;5:175-81.

12 Royds JA, Rennie IG, Parsons MA, Timperley WR, Taylor CB. Enolase isoenzymes in uveal melanomas-a possible parameter of malignancy. $\mathrm{Br} \mathrm{J}$ Ophthalmol 1983 (in press).

${ }^{13}$ Carney DN, Marangos PJ, Ihde DC, et al. Serum neurone-specific enolase: a marker for disease extent and response to therapy of small-cell lung cancer. Lancet 1982; I:583-5.

${ }^{14}$ Bolton AE, Hunter WM. The labelling of proteins to high specific radioactivities by conjugation to ${ }^{125}$ I containing acylating agent. Biochem $J$ 1973;133:529-39. 